\title{
Humoral immune reaction of newborn calves congenitally infected with Neospora caninum and experimentally treated with toltrazuril
}

Received: 22 March 2006 / Accepted: 29 March 2006 / Published online: 21 April 2006

C) Springer-Verlag 2006

\begin{abstract}
Neospora caninum is widely recognized as one of the most important infectious organisms causing abortion and stillbirth in cattle. This parasite causes severe economical losses worldwide. Infection is mostly passed vertically from mother to calf during pregnancy. Under certain circumstances, an infection can lead to abortion, but in most cases it results in a chronically infected calf, which itself will represent the next endogenously infectious generation. So far, no reliable therapeutic or metaphylactic tool has been developed. One possibility to control the problem may consist of treating newborn calves that became vertically infected by a persistently infected mother. This may allow parasite-free offspring. The aim of the present study was to address the questions: (1) can serology be used to assess efficiency of treatment in toltrazuril-medicated animals? and (2) is a strategic prevention measure possible by means of producing $N$. caninum-free calves from positive cows? Calves from Neospora-seropositive cows and heifers were randomly split into two different medication groups: 36 calves were medicated with toltrazuril and 36 calves obtained a placebo. Medication (20 mg toltrazuril per $\mathrm{kg}$ bw) was administered three times, every second day, within the 7 days post natum. Three months after medication, there was no difference in antibody reactivity between the two groups. At later time points (4-6 months), however,
\end{abstract}

\section{Haerdi $\cdot$ M. Haessig}

Herd Health, Department of Farm Animals, Vetsuisse Faculty, University of Zurich,

Winterthurerstr. 260,

CH-8057 Zurich, Switzerland

H. Sager · D. Staubli · B. Gottstein $(\bowtie)$

Institute of Parasitology, Vetsuisse Faculty, University of Bern,

Laenggass-Strasse 122,

$\mathrm{CH}-3012$ Bern, Switzerland

e-mail: bruno.gottstein@ipa.unibe.ch

Tel.: +41-31-6312418

Fax: +41-31-6312622

G. Greif

Bayer HealthCare AG, Animal Health,

51368 Leverkusen, Germany significant differences were found, as explained by a strong humoral immunity after chemotherapeutical affection of parasites, while the placebo-treated animals only responded weakly to the persistent infection. In summary, we concluded that (1) serology was not an entirely appropriate tool to answer our initial question and (2) toltrazuril has the potential to eliminate $N$. caninum in newborn calves. As a consequence, we plan to follow up toltrazuril-medicated calves clinically and serologically over a longer period and investigate if they give birth to Neospora-free calves.

\section{Introduction}

Neospora caninum is an important cause of infectious abortion and stillbirth in cattle worldwide. Infection is common and may frequently be passed on from mother to calf (endogenous transmission) with no signs of disease. Disease occurs when the parasite multiplies in the developing calf and in the maternal and fetal placenta, causing sufficient damage to trigger abortion or stillbirth (Dubey and Lindsay 1996). Infection of the fetus early in gestation is more likely to be fatal to the conceptus than infection later in gestation (Dubey 2003). However, it also appears that infection is more likely to be transmitted in late rather than early pregnancy. Thus, the majority of infections are not fatal, and, in this way, inapparent infections are maintained in a herd. Endogenous transmission upon reactivation of dormant parasites is the major route of prenatal infection, but it is also possible that oocysts of $N$. caninum, produced by dogs and excreted in their feces (McAllister et al. 1998), infect cattle if they ingest contaminated food or water (exogenous transmission mode). Control of bovine neosporosis is difficult. Although pharmaceutical preparations are known that will affect $N$. caninum in vivo (Gottstein et al. 2005), there is presently no validated and respectively registered therapeutical strategy that can be recommended for practical use to control the problem in the field, as referenced by PubMed. The alternative - vaccinating cattle to efficiently 
control the problem - is still controversial and also lacks proof of efficacy and efficiency (Andrianarivo et al. 2000; Innes et al. 2002).

Experimentally, nevertheless, there has been a series of studies that indicated some promising developments in view to chemotherapeutically affect $N$. caninum in vitro (Lindsay and Dubey 1989, 1990; Lindsay et al. 1994; Kim et al. 2002; Kwon et al. 2003; Youn et al. 2003). In vivo, the efficacy of treatment was less obvious, e.g., treatment of mice with sulfadiazine and amprolium did not provide sufficient effect (Lindsay and Dubey 1990). Toltrazuril, a symmetric triazinon derivative, has been shown to affect proliferating and resting stages of various coccidian parasites (Mehlhorn et al. 1984; Greif 2000; Greif et al. 2001). The exact mode of action is still not yet fully elucidated, but studies have shown that nuclear division is affected, the mitochondrial activity is impaired, and the endoplasmatic reticulum is vacuolized (Mehlhorn et al. 1984; Harder and Haberkorn 1989; Mitchell et al. 2005).

Explorative investigations had shown that toltrazuril can be effective against experimental neosporosis in the murine (Eperon et al. 1999; Gottstein et al. 2001; Darius et al. 2004) and bovine (Kritzner et al. 2002) model, and that an efficient metaphylaxis requires at least a T-cell-mediated immunological support in mice (Amman et al. 2004). We now recently showed that toltrazuril can contribute to the control of congenital neosporosis in mouse dams (Gottstein et al. 2005). Besides reducing abortion and infertility rates in pregnant mice, toltrazuril-treatment also affected directly the infection course in the fetuses, which is best demonstrated by the lack of postnatal death in offspring of toltrazuril-treated mothers vs postnatal death of some of the newborns of non-treated mothers (Gottstein et al. 2005). Although infected dams may remain carriers of the parasite, they seem not to act as sources of infection for the fetus in later pregnancies, conversely to the situation found in naturally infected cattle (Gottstein et al. 2005).

The present study was now designed to address the following questions: (a) Does treatment of infected newborn calves with toltrazuril, based upon the assumption that the parasite load is eliminated, indirectly affect the course of the humoral immune reaction of the host? A dichotomic hypothesis was followed, in that a rapid elimination of the parasite load should result in a temporally reduced serum antibody reactivity, whereas a slow action should rather transiently increase the respective anti- $N$. caninum antibody reactivity. The latter effect had already been described after anti-coccidial treatment of poultry by toltrazuril. (b) Can serology be used to assess efficiency of treatment in toltrazuril-medicated animals?

The reason for choosing the (indirect) humoral immune response as a follow-up parameter can be explained by the lack of appropriate tools to reliably detect $N$. caninum in vivo. Thus, the detection of parasite DNA in blood samples (Okeoma et al. 2004) was discussed but was rejected, as this approach does not provide a reliable way to persistently distinguish between parasite carriers and parasite-free animals. Even post mortem analyses of various organs of naturally (Wyss et al. 2000) or experimentally (Kritzner et al. 2002) infected animals showed that the diagnostic sensitivity of PCR, when compared to serology, was rather low, conversely to abortion material, where an usually high infection intensity can easily be detected by PCR.

The final control procedure we are anticipating with the present strategy includes the following options: treatment of newborn calves (from seropositive mothers) are relieved from their $N$. caninum infection, thus, culling would not anymore be necessary to obtain parasite-free offspring breeding lines. The cost-effectiveness of such a strategy may-beside the long-term reduction of the abortion ratebe supplemented by the fact that this strategy would allow to continue breeding of precious genetic lines, irrespective of the mother's infection status. The only alternative, so far, has been to transfer embryos from seropositive donors into seronegative recipient animals, a costly and time-consuming procedure.

Furthermore, creating seronegative breeding lines may also result in the improvement of other economic factors. Thurmond and Hietala (1996) showed that seropositive cows were earlier slaughtered than seronegative cows, and that this effect was not only attributed to the abortion problem but also to a reduced milk yield (Thurmond and Hietala 1997; Hernandez et al. 2001, 2002). Some authors even claimed a reduced gain of body weight in seropositive fattening calves (Barling et al. 2000, 2001).

A successful treatment of newborn calves would have further advantages to, e.g., treating adult cattle: the costs of therapy are significantly lower as a cause of the lower body weight and the withdrawal time of 63 days $^{1}$ is not relevant for newborn animals, compared to lactating cows. Upon successful outcome of the present investigation, follow-up studies are under design to prove that treated animals are parasite-free.

\section{Materials and methods}

\section{Gross study design}

The present matched-pair and double-blinded study was carried out under Good Clinical Practice (GCP) conditions. In the first step, $N$. caninum seropositive cows were preselected by ELISA (according to Sager et al. 2001) in 22 different cattle farms that had already been previously investigated (Haessig and Gottstein 2002). The study was run from May 2004 to March 2005. The farmer had to inform the investigator about birth of calves from designated seropositive cows immediately after delivery. If feasible, the farmer or the investigator would draw an umbilicord blood sample for subsequent pre-colostral serological investigations (precS). Each calf underwent a conventional clinical examination within 2 days post partum, including assessment of body weight and a first

${ }^{1}$ The recommended dosage for Baycox $5 \%$ oral suspension to treat coccidiosis in cattle is $20 \mathrm{mg} / \mathrm{kg}$ once. Residue studies proved a withdrawal period of 63 days after single treatment. 
post-colostral blood sampling (postcS_1). The mother animal was simultaneously blood sampled as well. The calf obtained the first dose of toltrazuril (Baycox 5\% suspension: $20 \mathrm{mg}$ totrazuril per $\mathrm{kg}$ body weight=vero) or placebo (suspension without active ingredient) at the same time point. A second identical dose was then applied $48 \mathrm{~h}$ later and a third and last one $96 \mathrm{~h}$ later. A first follow-up blood sample was drawn after approximately 3 months (postcS_2). The respective mean time point was 104 days after therapy (minimum 92 days; maximum 155 days). Twenty-eight of the calves were kept longer in the farm, thus, further samples were taken later (postcS_3 and postcS_4), the latest at day 387 post therapy.

The calves were randomly clustered into two groups: group I and group II. The affiliation of groups I and II to the placebo and vero groups was released after accomplishment of the experimental and analytical investigations. The treatment distribution was assigned to all animals before initiation of the study. An even number of calves was included for each farm, so that each vero-treated animal had a placebo-treated partner on the same farm (i.e., matched pair).

\section{Toltrazuril blood serum concentration}

Bood samples were collected from three placebo- and four vero-treated calves between days 10 and 12 as well as 30 and 32 after medication, respectively. Respective serum samples were stored frozen at $-18^{\circ} \mathrm{C}$ till further use. After thawing, the sera were deproteinized by mixing with acetonitrile and subsequent centrifugation. Analysis for concentrations of toltrazuril and toltrazuril-sulfone was determined by HPLC with detection by tandem mass spectrometry at the Laboratory for Animal Health, Bayer CropScience AG, Research and Development, Development, Residues, Operator and Consumer Safety, Monheim. The limit of quantitation was $0.025 \mathrm{mg} / \mathrm{l}$ for each analyte.

\section{Enzyme-linked immunosorbent-assay (ELISA)}

Serum samples $(n=143)$ were tested for detection of anti- $N$. caninum antibodies by using a commercial ELISA test CHEKIT at the laboratory of the Institute of Parasitology, University of Bern, Switzerland, following the manufacturers' instructions (Bommeli Diagnostics, Bern, http:// www.bommeli.com). This commercial test used microtiter plates that were coated with crude antigen lysates of whole tachyzoites. The test and control sera were diluted 1:10 and incubated for $60 \mathrm{~min}$ at $37^{\circ} \mathrm{C}$. Antibody reactivity was measured by the degree of color developed (absorbance measured at $405 \mathrm{~nm}$, reference wavelength $490 \mathrm{~nm}$ ). The results were expressed as percent reactivities (= relative antibody units, \%rAU) using the following formula:

$$
\text { Sample value }(\% \text { rAU }) \frac{\text { A sample }-F \times \text { A negative }}{\text { A positive }-F \times \text { A negative }} \times 100
$$

The factor $F$ determined the cutoff and was calculated from the mean absorption value of $40 \mathrm{~N}$. caninum-negative sera plus three standard deviations, divided by the absorption of the negative control $\left(A_{\text {negative }}\right)$. Values above the cutoff were defined as positive, those below as negative. Sample values, expressed as relative antibody units $(\%$ rAU), were, thus, brought into relation to the cutoff $(0 \%$ rAU) and the positive control $\left(A_{\text {positive }}=100 \%\right.$ rAU).

Serum samples were tested in triplicates. If the coefficient of variation was $\geq 0.10$, the most divergent value was ignored and the remaining two values were averaged. If there were no outliners identifiable, all three values were averaged.

\section{Statistics}

The software StatView 5.1 (SAS) was used to perform analysis of variance and analysis of variance with repeated measurements. The statistical analyses included only those animals that had at least one seropositive result in the whole series. Significant differences were determined with a $p$ value $<0.05$. Before applying parametric tests, the data were checked for their normal distribution.

\section{Results}

\section{Bodyweight of calves}

The average bodyweight for the calves from the placebo group was $44.4 \mathrm{~kg}$ (minimum $35 \mathrm{~kg}$, maximum $59 \mathrm{~kg}$ ) and that for the vero group $44.4 \mathrm{~kg}$ (minimum $33.5 \mathrm{~kg}$, maximum $57 \mathrm{~kg}$ ). There was no statistically significant difference between both groups.

\section{Serologies}

Dam serology The mean serum reactivities of both groups assessed by ELISA are shown in Fig. 1. There was no statistically significant difference between both groups.

Precolostral calf serology Precolostral sera could be obtained from 14 calves, from which eight samples were seropositive by ELISA. From six calves that were precolostrally seronegative, four seroconverted postcolosatrally, and two remained seronegative also postcolostrally, although their mother had been seropositive at the periparturient time point. The respective antibody reactivities of these two mother animals were very low, conversely to the four other mothers (data not shown). The postcolostral seroconversion and subsequent temporal follow-up of antibody reactivities of the four periparturiently seroconverting calves listed above are shown in Fig. 2. Two of these four calves belonged to the placebo group I, the other two to the vero group II. With the exception of calf no. 31 (vero group), the other animals exhibited a rapid decrease of antibody reactivities. 


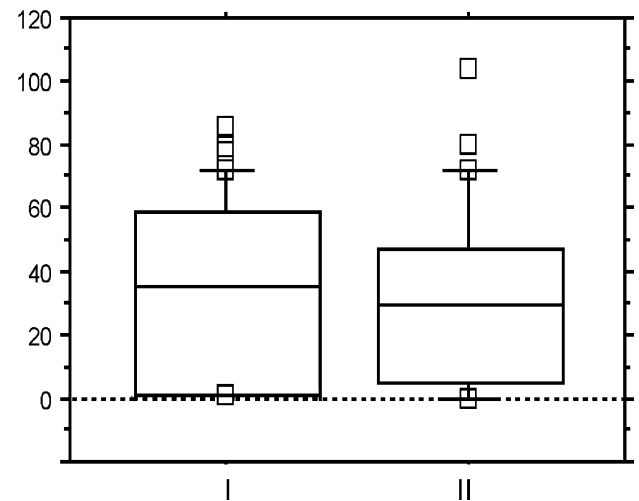

Fig. 1 Boxplot of periparturient mean antibody reactivities of the mother animals from group I (placebo group) and group II (vero group). Antibody reactivities are expressed in relative antibody units, \%rAU (see text)

Postcolostral calf serology Postcolostral follow-up of antibody reactivities of the calves from groups I and II are shown in Fig. 3. For all four time points (postcS 1, postcS_2, postcS_3, and postcS_4), the comparison between groups $\overline{\mathrm{I}}$ and group $\mathrm{II}^{-}$values provided no statistically significant difference as assessed by analysis of variance, although the mean values of group II appeared slightly higher at the time points postcS_3 $(p=0.19)$ and postcS $4(p=0.17)$.

Up to the time point postcS_2, four calves of group II and one of group I had converted from initially seropositive to now seronegative. At later time points, no more calf converted to seronegative anymore.

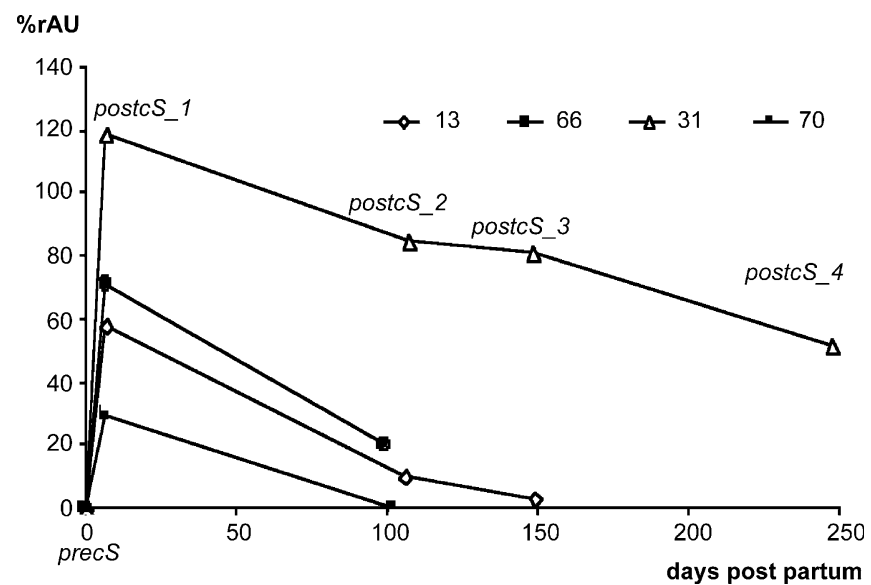

Fig. 2 Postcolostral follow-up of antibody reactivities (expressed in relative antibody units, \%rAU) of four calves that were precolostrally seronegative. Calves nos. 13 and 66 belonged to the placebo group, calves no. 31 and 70 to the vero group. "postcS 1" refers to the first postcolostral blood sampling at 1 to 3 days post partum (p.p.). "postcS 2" refers to a blood sample drawn approximately 3 months p.p. "postcS_3" and "postcS_4" refer to a total of 28 calves where further samples could be taken at later time points (between 180 and 387 days p.p.)
$\%$ rAU
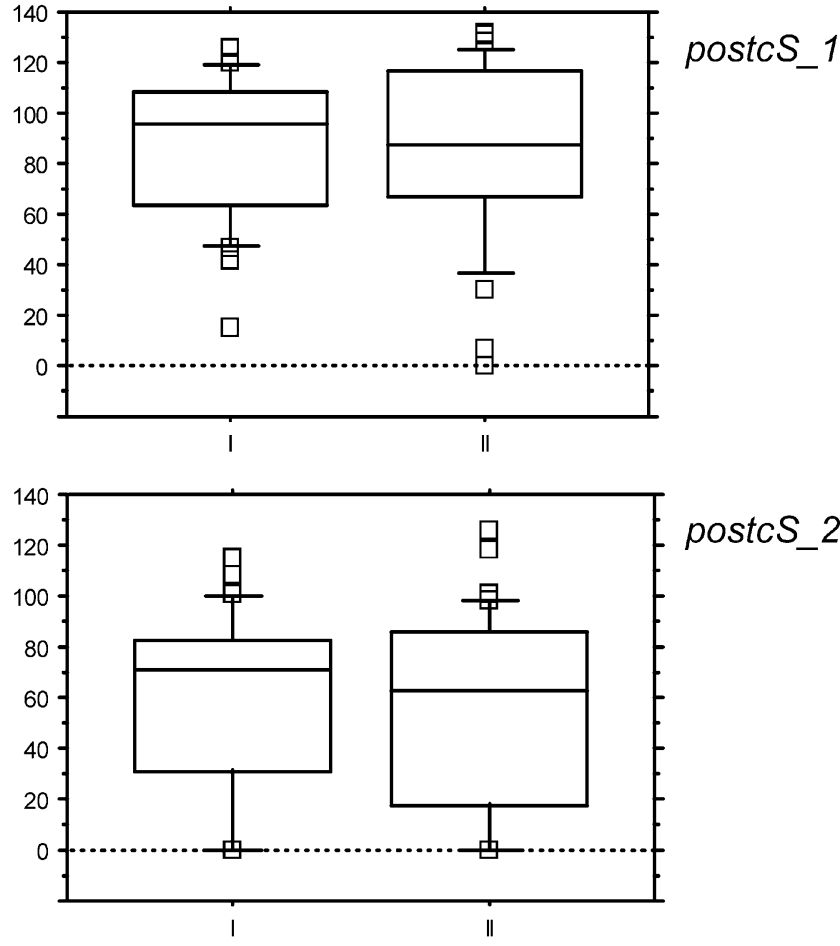

postcS_2

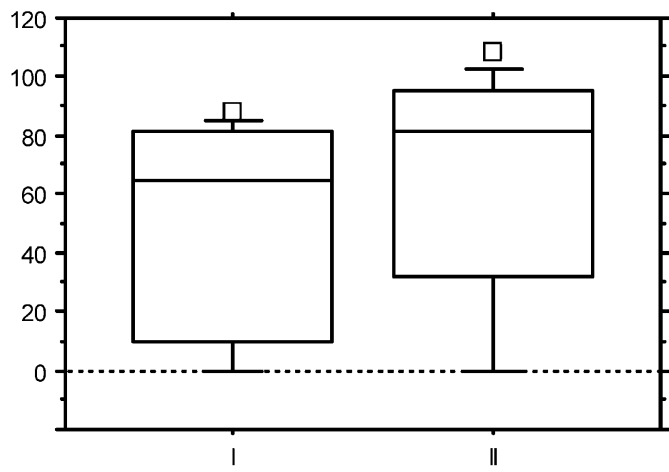

postcS_3

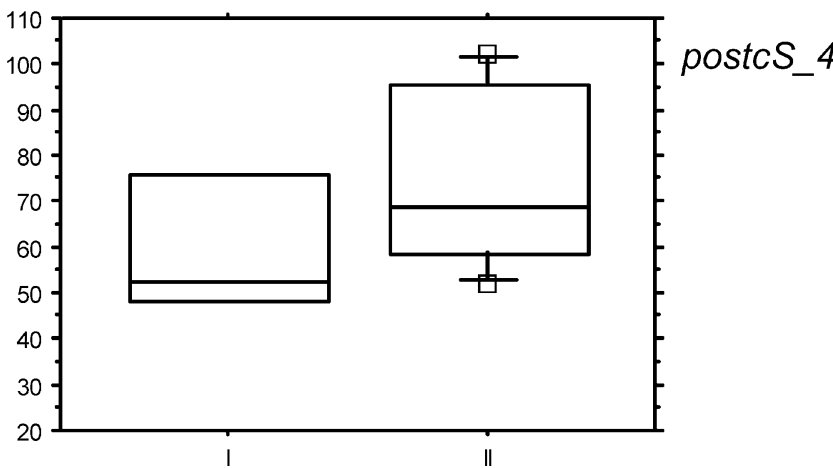

Fig. 3 Boxplot of postcolostral follow-up of antibody reactivities (expressed in relative antibody units, \%rAU) of calves from group I (placebo group) and group II (vero group). "postcS_1" refers to the first postcolostral blood sampling at 1 to 3 days post partum (p.p.). "postcS_2" refers to a blood sample drawn approximately 3 months p.p. "postcS 3" and "postcS 4" refers to a total of 28 calves where further samples could be taken at later time points (between 180 and 387 days p.p.) 
We subjected the postcolostral results altogether to an analysis of variance with repeated measurements (Fig. 4). With a $p=0.048$, the follow-up between postcS 1 and postcS 3 / postcS 4 , respectively, provided a statistically significant difference between groups I and II. The difference was obtained with an analysis of variance (ANOVA) with repeated measurements using the respective $A_{405} \mathrm{~nm}$ values as dependent variable, and time points together with animal groups (I and II) as independent variable, while the actual time point of sampling was used as covariate. At the initial time point postcS 1, no difference can be seen between groups I and II. Subsequently, the two groups diverge in that the placebo group (I) rapidly drops in antibody reactivity by each new time point, whereas, the vero-group values remain high till postcS 3, and then start to decrease till time point postcS 4 .

\section{Toltrazuril blood serum concentration}

Toltrazuril and toltrazuril-sulfone concentrations were determined in the serum samples by HPLC-MS/MS and provided the following findings: all samples from group I (placebo group) were negative, therefore, no drug concentrations were detected in the samples.

The group II samples exhibited a mean toltrazuril concentration of $31.7 \mathrm{mg} / \mathrm{l}$ (minimum 24.3, maximum 42.0 ) at the time points " $10-12$ days" and of $0.77 \mathrm{mg} / 1$ (minimum 0.52 , maximum 1.16 ) at the time points " 30 32 days". The values for Toltrazuril-sulfone were $74.4 \mathrm{mg} /$ 1 (minimum 53.6, maximum 95.9) and $63.1 \mathrm{mg} / 1$ (minimum 42.2, maximum 83.2), respectively.

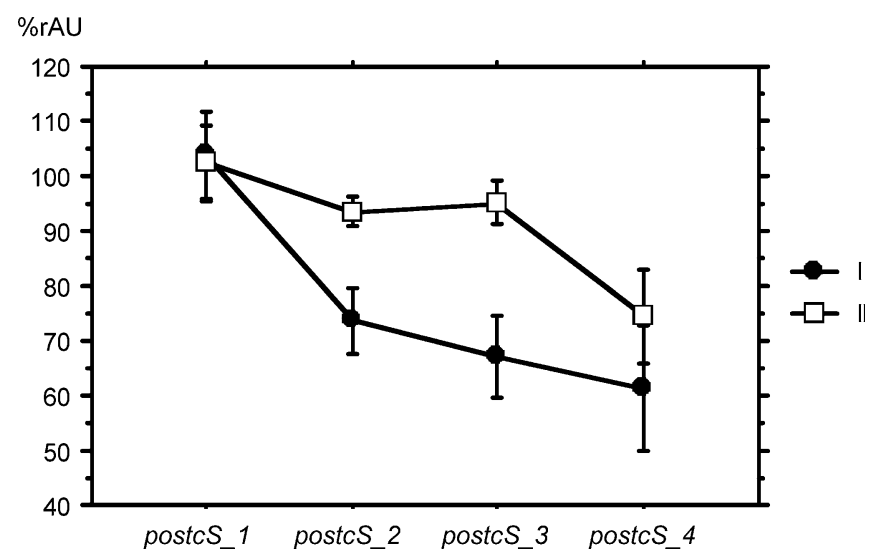

Fig. 4 ANOVA analysis with repeated measurements ( $p$ value $<0.05$ ) of antibody reactivities (expressed in relative antibody units, $\%$ rAU; mean and standard error) of calves from group I (placebo group) and group II (vero group) analysed by ELISA "postcS 1" refers to the first postcolostral blood sampling at 1 to 3 days post partum (p.p.). "postcS 2" refers to a blood sample drawn approximately 3 months p.p.. "postcS_3" and "postcS_4" refers to a total of 28 calves where further samples could be taken at later time points day (between 180 and 387 days p.p.)

\section{Discussion}

Within the range of potential means to control the bovine $N$. caninum-induced abortion problem, chemotherapy of newborn calves may reduce prevalence, provided the treatment effectively results in parasite-free offsprings (Haesler et al. 2006a, submitted for publication). Assessing the costs and benefit of a control strategy, which considers medical treatment of female offspring, resulted in a high benefit-cost ratio (Haesler et al. 2006b, submitted for publication). However, substances active against $N$. caninum are still under evaluation only, and their application under defined experimental conditions deserves detailed investigation and documentation before being proposed for field application. Within such investigations, we designed the present study to address the question if treatment of infected newborn calves with toltrazuril affects the course of the humoral immune reaction of the host. Immune parameters may become an important parameter in following-up experimentally treated cattle, as the direct determination of the parasite load and the parasite viability upon treatment is not possible in vivo.

In our experiments, 3 months after treatment of newborn calves either with vero or placebo, there was no difference in antibody reactivity between the two groups. As all calves were born from $N$. caninum-seropositive mothers, they all obtained a colostral passive immunity, including the four calves that exhibited a negative precolostral serology. The half-life period of such IgG is approximately 20 days, thus, we cannot expect a full negativation within 3 months, thus, colostral antibodies may exhibit a marked influence on the humoral immune status the earlier after birth tests are carried out. However, at a later time period (4-6 months), we were able to demonstrate significant differences, as shown by a stronger antibody reactivity expressed in verotreated animals when compared to placebo-treated calves. This may be explained by the induction of a strong humoral immunity after chemotherapeutical affection of parasites, while the placebo-treated animals only responded weakly to the persistent infection. At this time point, colostral antibodies, quantitatively, do not play a crucial role anymore. That humoral immunity raises after successful treatment with toltrazuril was shown in the avian coccidiosis model by Greif (2000). Furthermore, we have found in the murine model that toltrazuril-treatment requires the support of host immunity to successfully eliminate the parasite burden (Amman et al. 2004). Conversely, the treatment of mice with toltrazuril did not interfere with the development of a specific cellular intestinal immune response to Eimeria falciformis, another coccidian parasite affecting mice (Steinfelder et al. 2005). Still in the mouse model, besides reducing abortion and infertility rates in pregnant mice, toltrazuril-treatment also affected directly the infection course in the fetuses, which is best demonstrated by the lack of postnatal death in offspring of toltrazuril-treated mothers vs postnatal death of some of the newborns of non-treated mothers (Gottstein et al. 2005). Although infected dams may remain carriers of the parasite, they seem not to act as sources of infection for 
the fetus in later pregnancies, conversely to the situation found in naturally infected cattle (Gottstein et al. 2005).

As we did not find any significant differences in body weight between groups I and II, we can claim that treatment (vero) does directly not have any negative effect on the gain of body weight, but that a putative effective treatment of $N$. caninum also does not affect the body weight gain of the animals, at last within the time period of 4-6 months.

One question we addressed is if the immediate postnatal physiology of the digestive system in newborn calves allows a proper resorption of perorally administered toltrazuril, thus leading to the appropriate plasma level required to treat neosporosis. All animals investigated matched the requirements, and the calves exhibited plasma levels comparable to those experienced in elder animals before (Kritzner et al. 2002).

We now initiated a subsequent study to follow up toltrazuril-medicated calves clinically and serologically over a longer period, and to investigate if, once they became themselves animals of breeding age, they give birth to Neospora-free calves. Therefore, only the comparative long-term follow-up for more than one generation will help find the answer.

Acknowledgements We are grateful to Philip Stünzi, Ursula Brönnimann, and Christine Wittwer for technical assistance. The study was partially supported by the Swiss Federal Office of Science and Education (BBW C01.0122 in the frame of COST 854), Bayer HealthCare AG and the Department of Clinical Research (Vetsuisse Faculty in Bern).

\section{References}

Amman P, Waldvogel A, Breyer I, Esposito M, Müller N, Gottstein B (2004) The role of B- and T-cell immunity in toltrazuriltreated $\mathrm{C} 57 \mathrm{BL} / 6 \mathrm{WT}, \mu \mathrm{MT}$ and nude mice experimentally infected with Neospora caninum. Parasitol Res 93:178-187

Andrianarivo A, Rowe G, Barr JD, Anderson BC, Packham ML, Sverlow AE, Choromanski KW, Loui L, Grace C, Conrad PA (2000) A POLYGEN(TM)-adjuvanted killed Neospora caninum tachyzoite preparation failed to prevent foetal infection in pregnant cattle following i.v./i.m. experimental tachyzoite challenge. Int J Parasitol 30:985-990

Barling KS, Mcneill JW, Thompson JA, Paschal JC, Mccollum FT 3rd, Craig TM, Adams LG (2000) Association of serological status for Neospora caninum with postweaning weight gain and carcass measurements in beef calves. J Am Vet Med Assoc 217:1361-1365

Barling KS, Mcneill JW, Paschal JC, Mccollum FT 3rd, Craig TM, Adams LG, Thompson JA (2001) Ranch-management factors associated with antibody seropositivity for Neospora caninum in consignments of beef calves in Texas, USA. Prev Vet Med 52:53-61

Darius AK, Mehlhorn H, Heydorn AO (2004) Effects of toltrazuril and ponazuril on Hammondia heydorni (syn. Nespora caninum) infections in mice. Parasitol Res 92:520-522

Dubey JP (2003) Review of Neospora caninum and neosporosis in animals. Korean J Parasitol 41:1-16

Dubey JP, Lindsay DS (1996) A review of Neospora caninum and neosporosis. Vet Parasitol 67:1-59

Eperon S, Brönnimann K, Hemphill A, Gottstein B (1999) Susceptibility of B-cell deficient C57BL/6 ( $\mu \mathrm{MT})$ mice to Neospora caninum infection. Parasite Immunol 21:225-236
Gottstein B, Eperon S, Dai WJ, Cannas A, Hemphill A, Greif G (2001) Efficacy of toltrazuril and ponazuril against experimental Neospora caninum infection in mice. Parasitol Res 80:43-48

Gottstein B, Razmi GR, Amman P, Sager, Müller N (2005) Toltrazuril treatment to control diaplacental Neospora caninum transmission in experimentally infected pregnant mice. Parasitology 130:41-48

Greif G (2000) Immunity to coccidiosis after treatment with toltrazuril. Parasitol Res 86:787-790

Greif G, Harder A, Haberkorn A (2001) Chemotherapeutic approaches to protozoa: Coccidiae - current level of knowledge and outlook. Parasitol Res 87:973-975

Haessig M, Gottstein B (2002) Epidemiological investigation of abortions due to Neospora caninum on Swiss dairy farms. Vet Rec 150:538-542

Harder H, Haberkorn A (1989) Possible mode of action of toltrazuril: studies on two Eimeria species and Ascaris suum enzymes. Parasitol Res 76:8-12

Hernandez J, Risco C, Donovan A (2001) Association between exposure to Neospora caninum and mild production in dairy cows. J Am Vet Med Assoc 219:632-635

Hernandez J, Risco C, Donovan A (2002) Risk of abortion associated with Neospora caninum during different lactations and evidence of congenital transmission in dairy cows. J Am Vet Med Assoc 221:1742-1746

Innes EA, Andrianarivo AG, Björkmann C, Williams DJ, Conrad PA (2002) Immune response to Neospora caninum and prospects for vaccination. Trends Parasitology 18:497-504

Kim JT, Park JY, Seo HS, Oh HG, Noh JW, Kim JH, Kim DY, Youn HJ (2002) In vitro antiprotozoal effect of artemisinin on Neospora caninum. Vet Parasitol 103:53-63

Kritzner S, Sager H, Blum J, Krebber R, Greif G, Gottstein B (2002) An explorative study to assess the efficacy of toltrazurilsulfone (ponazuril) in calves experimentally infected with Neospora caninum. Ann Clin Microbiol Antimicrob 1:4

Kwon HJ, Kim JH, Kim M, Lee JK, Hwang S, Kim DY (2003) Anti-parasitic activity of depudecin on Neospora caninum via the inhibition of histone deacetylase. Vet Parasitol 112:269-276

Lindsay DS, Dubey JP (1989) Evaluation of anti-coccidial drugs' inhibition of Neospora caninum development in cell cultures. J Parasitol 75:990-992

Lindsay DS, Dubey JP (1990) Effects of sulfadiazine and amprolium on Neospora caninum (Protozoa: Apicomplexa) infections in mice. J Parasitol 76:177-179

Lindsay DS, Rippey NS, Cole RA, Parsons LC, Dubey JP, Tidwell RR, Blagburn BL (1994) Examination of the activities of 43 chemotherapeutic agents against Neospora aninum tachyzoites in cultured cells. Am J Vet Res 55:976-981

McAllister MM, Dubey JP, Lindsay DS, Jolley WR, Wills RA, McGuire AM (1998) Dogs are definitive hosts of Neospora caninum. Int J Parasitol 28:1473-1478

Mehlhorn H, Ortmann-Falkenstein G, Haberkorn A (1984) The effects of sym. Triazinones on developmental stages of Eimeria tenella, Eimeria maxima and E. acervulina: a light and electron microscopical study. Z Parasitenkd 70:173-182

Mitchell SM, Zajac AM, Davis WL, Kennedy TJ, Lindsay DS (2005) The effects of ponazuril on development of apicomplexans in vitro. J Eukaryot Microbiol 52:231-235

Okeoma CM, Williamson NB, Pomroy WE, Stowell KM, Gillespie L (2004) The use of PCR to detect Neospora caninum DNA in the blood of naturally infected cows. Vet Parasitol 122:307-315

Sager H, Fischer I, Furrer K, Strasser M, Waldvogel A, Boerlin P, Audige L, Gottstein B (2001) A Swiss case-control study to assess Neospora caninum-associated bovine abortions by PCR, histopathology and serology. Vet Parasitol 102:1-15

Steinfelder S, Lucius R, Greif G, Pogonka T (2005) Treatment of mice with the anticoccidial drug Toltrazuril does not interfere with the development of a specific cellular intestinal immune response to Eimeria falciformis. Parasitol Res 97:458-465 
Thurmond MC, Hietala SK (1996) Culling associated with Neospora caninum infection in dairy cows. Am J Vet Res 57:1559-1562

Thurmond MC, Hietala SK (1997) Effect of Neospora caninum infection on milk production in first-lactation dairy cows. J Am Vet Med Assoc 210:672-674
Wyss R, Sager H, Müller N, Inderbitzin F, König M, Audigé L, Gottstein B (2000) Untersuchungen zum Vorkommen von Toxoplasma gondii und Neospora caninum unter fleischhygienischen Aspekten. Schweizer Arch Tierheilkd 142:95-108

Youn HJ, Lakritz J, Kim DY, Rottinghaus GE, Marsh AE (2003) Anti-protozoal efficacy of medicinal herb extracts against Toxoplasma gondii and Neospora caninum. Vet Parasitol 116:7-14 